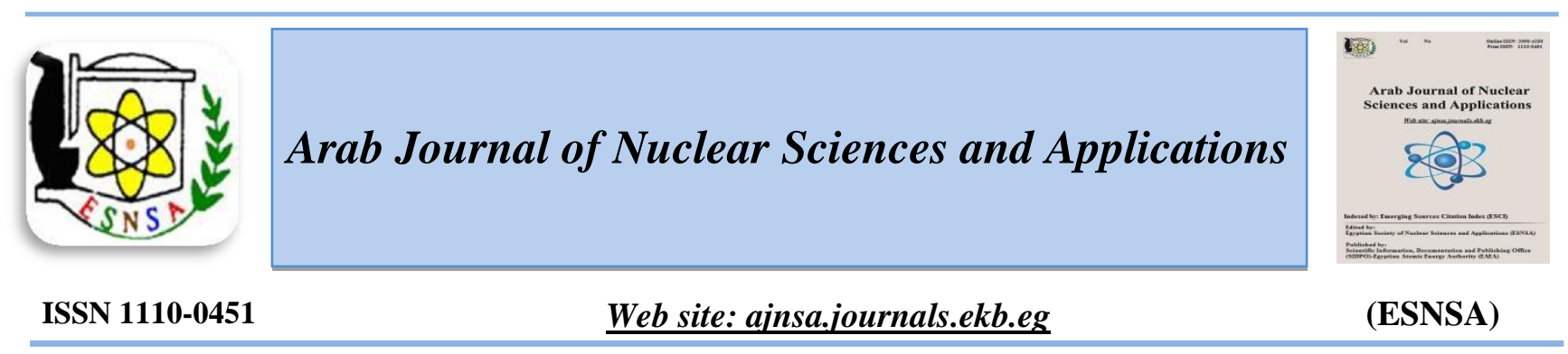

\title{
Effect of Grain Size on Radon Exhalation Rate from Calcium Silicate Rocks Using Alpha Track Detector
}

\author{
Hesham A. Yousef \\ Physics Department, Faculty of Science, Suez University, Suez, Egypt
}

Received $17^{\text {th }}$ Oct. 2018 Accepted 24 ${ }^{\text {th }}$ Apr. 2019

\section{Introduction}

Radon is the most important natural radioactive element harmfully influencing the human population, because it is a radioactive gas coming from the natural decay of uranium deposits in soil, rocks, and water. Radon is harmful to the environment and humans [1]. Its half-life of 3.82 days with alpha energy $5.49 \mathrm{MeV}$. Radon progenies are ${ }^{218} \mathrm{Po}$ and ${ }^{214} \mathrm{Po}$ emits alpha particles, which humans breath it and enter the human body. Radon emanation depends on the soil properties such as porosity, permeability, and the presence of cracks. Radon can be transported through the soil, building materials and enter the dwelling. Radon generates from most of the building materials, in which radium is one of its components [2, 3].Radon easily leaves the soil and rocks, by escaping into cracks and openings in rocks and into the pore spaces between grains of soil. Radon moves more readily through permeable soils, such as coarse sand and gravel, than through impermeable soil, such as clay. Cracks in any soil or rock allow radon to move more rapidly $[4,5]$.
Building and industrial materials, which are brought from the deserts like sands, and rocks, also contribute to environmental radioactivity by releasing radon gas, its radioactive daughters, which are deposited in the human respiratory tract [6]. Radon is formed in buildings through the soil, hence the radon exhalation rate from the building materials is an important parameter to estimate local environmental radon levels. The concentration of radon and its decay products changes due to variations by different factors like temperature, pressure, building materials, ventilation conditions.

Studies of radon geology include research into how radon sources are emitted from rocks, soil, and how radon moves. These studies also aim at identifying the hazard limits of these radioactive progenies, because radon and its decay products are widely known to be dangerous to human health. It is commonly associated with different types of cancer, and especially with lung cancer [7, 8].

Corresponding author: h_yosef2013@yahoo.com

DOI: 10.21608 /ajnsa.2019.5729.1129

(C) Scientific Information, Documentation and Publishing Office (SIDPO)-EAEA 
Calcium silicates have been used in many industries and their most important applications are the uses in building materials, such as some types of glass and cement (especially Portland cement), bricks and tiles for roofs, and building boards. The compound is also used as a filler in the manufacture of paper and some types of plastics $[9,10]$.

Calcium silicate is commonly used in asbestos as a high temperature insulation material. Industrialgrade piping and equipment insulation are often made from calcium silicate. Although it is popularly considered an asbestos substitute, early uses of calcium silicate for insulation still make use of asbestos fibers $[11,12]$.The exhalation rate depends on: radium concentration, emanation factor of radon, porosity and density of the material. Also, the radioactivity of the soil depends on grain size [13].Due to the diffusion and convection, the radon can be exhaled from the pore space into the air. The radon exhalation greatly depends on the features of the investigated material, such as the internal structure and the moisture content. Soils of high porosity increase possibility for radon to be emitted from the grain surface and leads to increase soil radon concentration. It was suggested by previous studies that the radioactivity of the soil is related to the grain size of soil [4]. The etched track detection technique is the most important technique used for time integrated radiation monitoring. This technique has been used in many studies for radon measurements. Radon monitoring in the air can be done outdoor, indoor, and in the mining environment $[14,15,16]$. The present study aimed to estimate the effect of grain size on radon concentration and the exhalation rate from calcium silicate rock samples. This is helpful in geological and radiological studies, because the determination of radon in the environment is of importance in the assessment of possible radiological hazards and risks to human health.

\section{Materials And Methods}

Ten samples of calcium silicate rocks of different grain sizes were measured using Closed Can Technique, with CR-39detector (CR-39 material is $\mathrm{C}_{12} \mathrm{H}_{18} \mathrm{O}_{7}$ and $500 \mu \mathrm{m}$ thickness with area of $1.5 \times 1.5 \mathrm{~cm}$ from American Technical Plastic, Inc.) to estimate the effect of grain size on radon concentration and radon exhalation rate. All samples are from the same material. These raw materials are used for the manufacture of cement and used in different industry. The chemical composition of this material was measured using $\mathrm{X}$-ray fluorescence analysis (XRF)as shown Table (1). The samples were dried, crushed, and passed through sieves with different pore sizes (In Geology Department, Faculty of Science, Mansoura University) in order to prepare samples with different grain sizes as shown in Table (2).

The sample is kept in cylindrical metal containers with dimension $17 \mathrm{~cm}$ high $\times 10.5 \mathrm{~cm}$ diameter. CR39 detectors are fixed on the bottom of the lid of each container with tape. The containers is tightly closed from the top and sealed for 30 days. After irradiation time, the detectors were collected from containers, and chemically etched. This process was carried out using $\mathrm{NaOH}$ (purity $98 \%$ from India).A6.25 N solution was kept in a water bath at $\left(70 \pm 1{ }^{\circ} \mathrm{C}\right)$ for $8 \mathrm{hr}$. After etchingCR-39 was washed in distilled water, and put ten minutes in a $5 \% \mathrm{CH}_{3} \mathrm{COOH}$ solution and washed with distilled water, then dried in air. The tracks produced by the alpha particles in the detector are counted under an optical microscope (Nikon - made in Japan)with magnification 640x, and the background subtracted from all counts of the samples[17]. Track densities were calculated by using the following relation:

$\rho=\frac{\sum N}{n \cdot A}$

$\mathrm{A}$ is the field of view area, $\sum \mathrm{N}$ is the total number of tracks, and $\mathrm{n}$ is the total number of fields of views[18].

Table (1):Analyzing the composition of the studied samples using XRF

\begin{tabular}{llllllllll}
\hline Oxide & $\mathrm{SiO}_{2}$ & $\mathrm{Al}_{2} \mathrm{O}_{3}$ & $\mathrm{Fe}_{2} \mathrm{O}_{3}$ & $\mathrm{CaO}$ & $\mathrm{MgO}$ & $\mathrm{SO}_{3}$ & $\mathrm{~K}_{2} \mathrm{O}$ & $\mathrm{Na}_{2} \mathrm{O}$ & $\mathrm{Cl}$ \\
\hline $\begin{array}{l}\text { Percent } \\
\text { content }\end{array}$ & 0.04 & 0.01 & 0.01 & 56.46 & 0.27 & 0.02 & 0.003 & 0.034 & 0.019 \\
\hline
\end{tabular}


Effect of Grain Size on Radon Exhalation Rate ......

Radon concentration in air is calculated using the following relation:

$$
C=\frac{\rho}{K . T}
$$

Where $\mathrm{C}$ : radon concentration $\left(\mathrm{Bqm}^{-3}\right), \mathrm{T}$ : exposure time, $\rho$ : track density, and $\mathrm{K}$ : calibration factor of the CR-39. The surface exhalation rate was given by:

$$
E_{A}=\frac{C V \lambda}{A \cdot\left[T+\frac{1}{\lambda}\left(e^{-\lambda T}-1\right)\right]}
$$

Where, $\mathrm{E}_{\mathrm{A}}$ : exhalation rate $\left(\mathrm{Bqm}^{-2} \mathrm{~h}^{-1}\right), \lambda$ : radon decay constant $\left(\mathrm{h}^{-1}\right), \mathrm{C}$ : integrated radon $\left(\mathrm{Bqm}^{-3} \mathrm{~h}\right)$, $\mathrm{V}$ : effective volume of the container $\left(\mathrm{m}^{3}\right), \mathrm{T}$ : irradiation time and A: cross section area of the container $\left(\mathrm{m}^{2}\right)$ [19].

\section{Results And Discussion}

The measured values of track density, exhalation rates $\left(\mathrm{E}_{\mathrm{A}}\right)$, and radon concentrations $\left(\mathrm{C}_{\mathrm{Rn}}\right)$ are presented for the samples of different grain size obtained by sieving the samples through different sieves as shown in Table (3). The values of track density ranged from $(592 \pm 56)$ to $(2837 \pm 143)$ track $\mathrm{cm}^{-2}$, and the values of $\mathrm{C}_{\mathrm{Rn}}$ ranged from $(41.11 \pm 3.89)$ to $(197.01 \pm 9.93) \mathrm{Bqm}^{-3}$. The measured values of surface exhalation rate were found to be $(8.98 \pm 0.85)-(43.05 \pm 2.17) \mathrm{mBqm}^{-2} \mathrm{~h}^{-}$ ${ }^{1}$ in the samples having powder grain size and 2.5 $m m$ respectively. The measured values of $C_{R n}$ and $\mathrm{E}_{\mathrm{A}}$ depend strongly on the physical sample parameters (grain size).

\begin{tabular}{|c|c|c|c|}
\hline Sample Code & $\begin{array}{l}\text { Standard } \\
\text { size }\end{array}$ & $\begin{array}{c}\text { Sample } \\
\text { classification }\end{array}$ & $\begin{array}{c}\text { Size range } \\
(\mathbf{m m})\end{array}$ \\
\hline G1 & $\mathrm{P}$ & \multirow{3}{*}{ Mud } & $\mathbf{G}=$ Powder \\
\hline G2 & $1 / 32$ & & Powder $<\mathrm{G} \leq 0.03125$ \\
\hline G3 & $1 / 16$ & & $0.03125<\mathrm{G} \leq 0.0625$ \\
\hline G4 & $1 / 8$ & Very fine sand & $0.0625<\mathrm{G} \leq 0.125$ \\
\hline G5 & $1 / 4$ & Fine sand & $0.125<\mathrm{G} \leq 0.25$ \\
\hline G6 & $1 / 2$ & Medium sand & $0.25<\mathrm{G} \leq 0.5$ \\
\hline G7 & 1 & Coarse sand & $0.5<\mathrm{G} \leq 1$ \\
\hline G8 & 1.5 & $\begin{array}{l}\text { Very Coarse } \\
\text { Sand }\end{array}$ & $1<\mathrm{G} \leq 1.5$ \\
\hline G9 & 2 & Gravel & $1.5<\mathrm{G} \leq 2$ \\
\hline G10 & 2.5 & Gravel & $2<\mathrm{G} \leq 2.5$ \\
\hline
\end{tabular}

Table (2): The values of size range, and the samples classification

Table (3): Track density, $C_{R n}$ and $E_{A}$ for the studied samples

\begin{tabular}{cccc}
\hline $\begin{array}{c}\text { Sample } \\
\text { Code }\end{array}$ & $\begin{array}{c}\boldsymbol{\rho} \\
\left(\mathbf{T r a c k} \mathbf{~ c m}^{-\mathbf{2}}\right)\end{array}$ & $\begin{array}{c}\mathbf{C}_{\mathbf{R n}} \\
\left(\mathbf{B q m}^{-\mathbf{3}}\right)\end{array}$ & $\begin{array}{c}\mathbf{E}_{\mathbf{A}} \\
\left(\mathbf{m B q m}^{-2} \mathbf{h}^{-\mathbf{1}}\right)\end{array}$ \\
\hline $\mathbf{G 1}$ & $592 \pm 56$ & $41.11 \pm 3.89$ & $8.98 \pm 0.85$ \\
$\mathbf{G 2}$ & $606 \pm 66$ & $42.08 \pm 4.58$ & $9.19 \pm 1.00$ \\
$\mathbf{G 3}$ & $657 \pm 69$ & $45.63 \pm 4.80$ & $9.97 \pm 1.05$ \\
$\mathbf{G 4}$ & $722 \pm 72$ & $50.14 \pm 5.00$ & $10.96 \pm 1.10$ \\
$\mathbf{G 5}$ & $1003 \pm 85$ & $69.65 \pm 5.90$ & $15.22 \pm 1.29$ \\
$\mathbf{G 6}$ & $1429 \pm 102$ & $99.24 \pm 7.08$ & $21.68 \pm 1.55$ \\
$\mathbf{G 7}$ & $1833 \pm 115$ & $127.29 \pm 7.98$ & $27.81 \pm 1.74$ \\
$\mathbf{G 8}$ & $2295 \pm 129$ & $159.38 \pm 8.96$ & $34.82 \pm 1.96$ \\
$\mathbf{G 9}$ & $2505 \pm 134$ & $173.96 \pm 9.31$ & $38.01 \pm 2.03$ \\
$\mathbf{G 1 0}$ & $2837 \pm 143$ & $197.01 \pm 9.93$ & $43.05 \pm 2.17$ \\
\hline
\end{tabular}

It is clear that from Table (3) that the values of track density and radon concentration increase with the increase in the grain size. Figures (1) and (2) show an increase in track density and radon concentration with the grain size. This refers to the increase in pore space between the grains. These wide spaces increase the diffuse of radon from the materials. For dwelling, ICRP recommended that 
the permissible limit of radon concentration equal (200 to 600) $\mathrm{Bqm}^{-3}[20]$. CR-39 used to measure indoor and outdoor radon concentration. However, there is some error percentage which could be attributed to the detector sensitivity, etching process and counting technique.

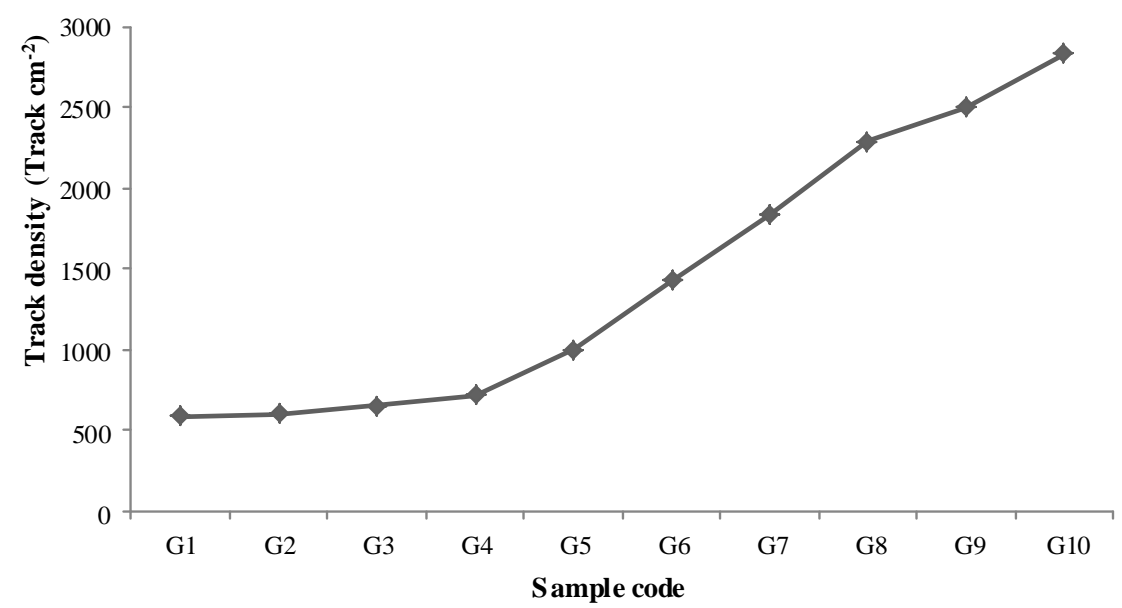

Figure (1): The relation between sample code of grain size and track density of the studied samples

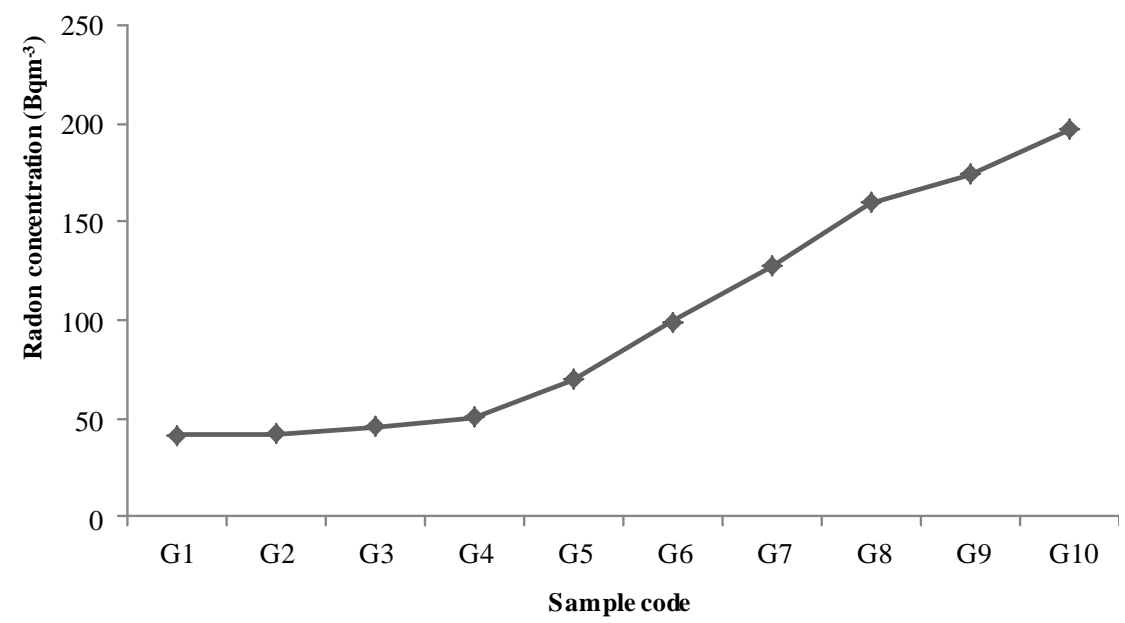

Figure (2): The relation between sample code of grain size and radon concentration 


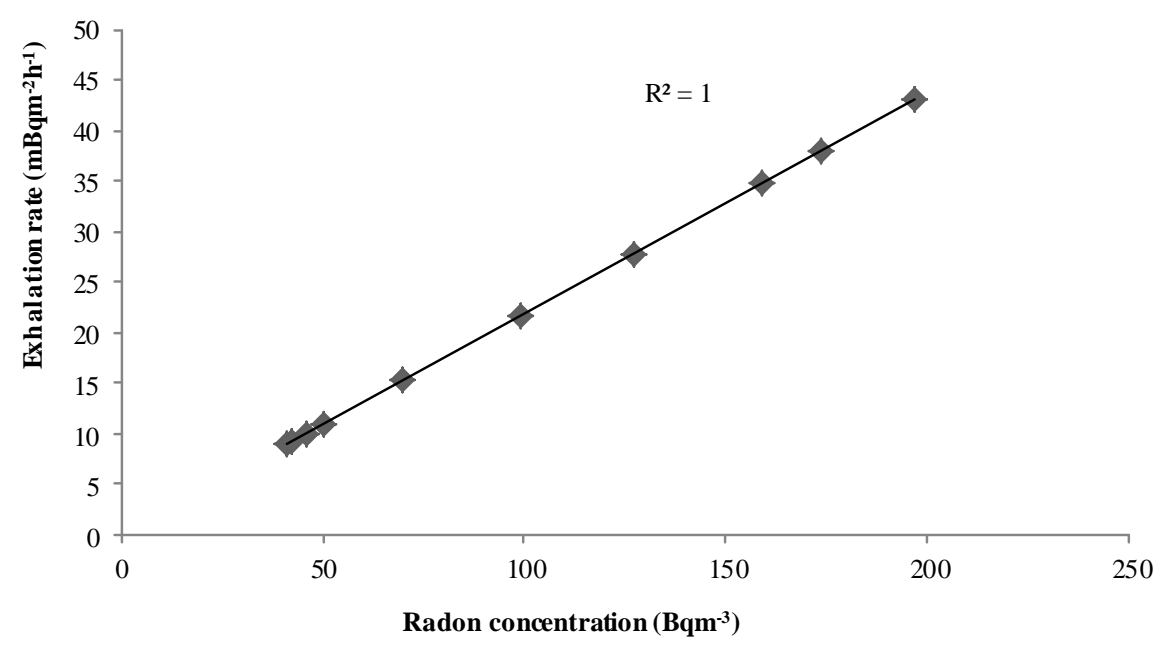

Figure (3): The correlation relation between $C_{R n}$ and $E_{A}$

Figure (3), shows a good linear correlation (positive correlation) between $\mathrm{C}_{\mathrm{Rn}}$, and $\mathrm{E}_{\mathrm{A}}$ for the samples. The correlation coefficient is linear because the values of $E_{A}$ depend on $C_{R n}$ since the sample surface area, container volume, and radon decay constant are the same for all samples. The values of $C_{R n}$ and $E_{A}$ changed from sample to another due to the difference in the sample grain size. Measurement of $E_{A}$ is important to know the relative contribution of radon concentration in the samples, and useful to know radiological hazards. The results are in agreement with similar studies carried out before[21, 22, 23].

\section{Conclusion}

The present work may be considered as an additional data base in the field of building materials to assess any changes in the radioactive background level in our houses. Radon exhalation rate depends on the physical parameters like grain sizes, which help in the assessment of possible radiological hazards and risks to human health.

The measured values of $E_{\mathrm{A}}$ ranged from 8.98 to $43.05 \mathrm{mBqm}^{-2} \mathrm{~h}^{-1}$ for the studied samples. There is a variation in radon exhalation rate from one sample to another, which depends on the physical formation. The results of $E_{A}$ for all samples are below the world average value of $57.60 \mathrm{Bqm}^{-2} \mathrm{~h}$ ${ }^{1}$ [24]. From the obtained results, it can be concluded that the surface exhalation rate increases with increasing grain size. From this point of view cement material must be fine in order to prevent or decrease the radon exhalation rate from the building.

\section{References}

1-Swakon, J., Kozak, K., Paszkowski, M., Gradzinski, R., Loskiewicz, J., Mazur, J., Janik, M., Bogacz, J., Horwacik, T. and Olko, P. Radon concentration in soil gas around local disjunctive tectonic zones in the Krakow area. J. Environ. Radioact., 78, pp. 137-149 (2005).

2-Singh A. K., Kumar Ashavani and Prasad Rajendra. Distribution of radon levels in Udaipur. Asian $\mathbf{J}$. Chem., 18 (5), pp. 3408-3411(2006).

3-Chauhan, R. P., Nain M., and Kant K.Radon diffusion studies through some building materials: Effect of grain size. J.Radiat. Meas., 43, pp. 445-448(2008).

4-Khayrat A. H., Oliver M. A., and Durrani S.A.The effect of soil particle size on radon concentration. J.Radiat. Meas., 34(365), pp.365-371(2001).

5-Aburnurad K. M., and Al Tamimi M.Emanation power of radon and its concentration in soil and rocks.J. Radiat. Meas., 34, pp. 423-426 (2001).

6-Quindos, L.S., Femandez, P.L., and Soto J. Building materials as source of exposure in houses. In: Seifert, B. Esdorn H. (Eds.), Indoor Air, 87 (2), Institute for water, soil and air hygiene, Berlin, pp. 365(1987).

7-IAEA, 2003. Radiation Protection against Radon in Workplaces other than Mines. Safety Reports Series No. 33, IAEA, Vienna, 2003.

8-Abdalsattar, K. H., Laith, A. N., Abbas, F. H., Fadhil, K. F. Lung cancer risk due to radon in different brand cigarette tobacco in Iraqi market. WSN. 77(2), pp. 163-176 (2017).

9-WWW.beechems.com/calcium-silicate.html.

10-Ko H., Jeong Y., and Kim M. Cytotoxicities and genotoxicities of cements based on calcium silicate and of dental form cresol. J. Mutat. Res., 815, pp. 28 34 (2017).

11-Liu Quanxiao, Yin Yanna, and XuWencai. Study on application of hydrated calcium silicate in paper from wheat straw pulp. J. Adv. Mat. Res., Vol. (774-776), pp. 1277-1280 (2013). 
12-Skaug V., Davies R., and Gylseth B. In vitro macrophage cytotoxicity of five calciumsilicates. British J. Industrial Medicine, 41, pp. 116-121(1984).

13-Jong Ede, Acton DF, and Kozak LM. Naturally occurring gamma emitting isotopes, radon release and properties of parent material of Saskatchewan Soils. Can J Soil Sci., 74, pp. 47-53(1993).

14-Reimer G.M., and Gunderson L.C.S. A direct correlation among indoor $\mathrm{Rn}$, soil gas $\mathrm{Rn}$ and geology in the reading prong near Boyertown, Pennsylvania. J. Health Phys., 57(1), pp. 155-60 (1989).

15-Shweikani R., Giaddai T. G., and Durrani S. A. The effect of soil parameters on the radon concentration values in the environment. J. Radiat. Meas., $25 \mathrm{pp}$. 581-84 (1995).

16-Faheem M, Matiullah. Radon exhalation and its dependence on moisture content from samples of soil and building materials. J. Radiat. Meas., 43 pp. 145862 (2008).

17-Hesham A. Yousef. Effect of alpha particles on the bulk etching rate of CR-39 nuclear track detector. J.Nucl. Part. Phys.,7(2), pp. 23-26(2017).

18-Hesham A. Yousef. Assessment of the annual effective dose of bottled mineral waters using Closed Can technique.J. Adv. Phys., 14(3),pp. 5696-5707 (2018).

19-Hesham A. Yousef, Gehad M. Saleh, El-Farrash A. H., and Hamza A. Radon Exhalation Rate for
Phosphate Rocks Samples Using Alpha Track Detectors" J Radiat. Res. Appl. Sci., 9, pp. 4146(2016).

20-ICRP, 1993. Protection against radon at home and at work. Ann., ICRP 23, publication 65, Pergamon, Oxford, 1993.

21-RajKumari, Krishan Kant, and ManeeshaGarg. The effect of grain size on radon exhalation rate in natural-dust and stone-dust samples. J. Phys. Procedia, 80, pp. 128-130(2015).

22-Tabassum Nasir and Nisar Ahmad.The effect of grain size on radon exhalation rate in soil samples of Dera Ismail Khan in Pakistan. J. Bas. Appl. Sci., 8, pp. 430-436(2012).

23-Rashmi, K. Kant, and G.S. Sharma.Activity measurements and dependence of radon exhalation rate on physical sample parameters in soil samples. Asian J. Chem., 21(10), pp. 271-274(2009).

24-UNSCEAR, 2000. (United Nations Scientific Committee on the Effects Of atomic Radiation to the General Assembly). Appendix I: Epidemiological evaluation of radiation induced cancer; Appendix G: Biological effects of low radiation doses. 